\title{
Conteúdos procedimentais nos livros didáticos de Ciências e Biologia: um olhar sobre as atividades propostas para os estudantes.
}

\author{
Procedural contents in Science and Biology textbooks: a look on the \\ activities propose to student.
}

Delano Moody Simões da Silva1; Ana Júlia Pedreira² ${ }^{2}$ Letícia Anjos³ ${ }^{3}$ Lucas Freitas Pereira Carneiro $^{4}$, Iago Oliveira ${ }^{5}$, Maria Eduarda Peres de Oliveira ${ }^{6}$, Bernardo Oricchio-Rodrigues ${ }^{7}$, Rosinaldo Domingos de Oliveira Melo ${ }^{8}$, Josiane Siqueira Quintas 9 , Yngrid Ribeiro ${ }^{10}$, Janyla Martins de Sousa ${ }^{11}$, Fabricio França Lemos ${ }^{12}$.

\begin{abstract}
1 Doutor em Ecologia (UnB), Faculdade UnB Planaltina, Brasília, Distrito Federal, Brasil - delanomoody@gmail.com, /ORCID: https://orcid.org/0000-0002-6784-6161

2 Doutora em Educação (UnB), Universidade de Brasília, Brasília, Distrito Federal, Brasil - anajuliapedreira@unb.br, /ORCID: https://orcid.org/0000-0003-2124-1789

3 Mestre em Ensino de Ciências (UnB), Secretaria de Educação do DF, Brasília, Distrito Federal, Brasil anjos.leticiafernanda@gmail.com, /ORCID: https://orcid.org/0000-0001-7595-5897

4 Mestre em Ensino de Ciências (UnB), Secretaria de Educação do DF, Brasília, Distrito Federal, Brasil lucas.yoshimitsu@gmail.com, /ORCID: https://orcid.org/0000-0001-9116-6716

5 Mestre em Ensino de Ciências (UnB), Universidade de Brasília, Brasília, Distrito Federal, Brasil - iago.gross@gmail.com, /ORCID: https://orcid.org/0000-0002-2707-1146

6 Mestre em Ensino de Ciências (UnB), Secretaria de Educação do DF, Brasília, Distrito Federal, Brasil meduardaunb@gmail.com, /ORCID: https://orcid.org/0000-0001-5201-8681

7 Mestre em Ensino de Ciências (UnB), Secretaria de Educação do DF, Brasília, Distrito Federal, Brasil bernardooricchio@gmail.com, /ORCID: https://orcid.org/0000-0002-4720-4014

8 Mestre em Ensino de Ciências (UnB), Secretaria de Educação do DF, Brasília, Distrito Federal, Brasil rosinaldo.dregama@gmail.com, /ORCID: https://orcid.org/0000-0002-8801-2262

9 Mestre em Ensino de Ciências (UnB), Secretaria de Educação do DF, Brasília, Distrito Federal, Brasil josianesiqquintas@gmail.com, /ORCID: https://orcid.org/0000-0003-4080-1526

10 Mestre em Ensino de Ciências (UnB), Secretaria de Educação do DF, Brasília, Distrito Federal, Brasil yngridsribeiro@gmail.com, /ORCID: https://orcid.org/0000-0002-6135-8204

11 Licenciada em Ciências Biológicas, Secretaria de Educação do DF, Brasília, Distrito Federal, Brasil janyllams@gmail.com, /ORCID: https://orcid.org/0000-0002-4553-0481

12 Licenciado em Ciências Biológicas, Secretaria de Educação do DF, Brasília, Distrito Federal, Brasil fabricio.consultor@yahoo.com.br, /ORCID: $\underline{\text { https://orcid.org/0000-0003-1287-4170 }}$
\end{abstract}

Recebido em Março/2019. Publicado em Agosto/2020 
Palavras-chave: Ensino de Ciências. Ensino de Biologia. Natureza dos conteúdos. análise de livros didáticos.

\section{Keywords:}

Science teaching. Biology teaching. nature of contents. textbook analysis.

\section{INTRODUÇÃO}

Já existe um consenso entre professores e pesquisadores da área de ensino de ciências que para ensinar e aprender Ciências é necessário irmos além da abordagem exclusivamente conceitual, a qual na maioria das vezes valoriza a memorização de conceitos e definições, e trabalharmos também procedimentos, atitudes e valores que estão relacionados com o aprender e o fazer Ciência (ANSÓN e TORIJA, 2017). É fundamental que ao ensinar Ciências sejam respeitadas as relações existentes entre conceitos, procedimentos e atitudes, pois caso contrário corremos o risco de não ensinarmos nem um, nem outro (ORÓ, 1999). Além disso, como afirma Kelly (2014), aprender Ciências não é só aprender os

ABSTRACT: The approach to procedures in science teaching is as necessary as the traditional conceptual approach. However, different from concepts, procedures need to be worked with activities that enable students to perform actions other than just listening and copying. Thus, in an attempt to verify the contribution that textbooks can bring to the teacher to address science-related procedures, this paper presents an analysis of the activities proposed in current textbooks of Biology and Sciences. Ten textbooks were chosen for this study, in which all the activities present were mapped and classified according to their objectives. After this phase it was analyzed if the activities contributed to develop the procedures proposed by Pozo and Crespo (2009). The books analyzed presented a significant and diverse number of activities, but they prioritize some types of activities, such as review and memorization, which do not contemplate all the procedures related to Sciences. As no type of activity contemplates all the procedures, it is important that the teacher uses the different types to contemplate all the proposed procedures. Knowing textbook and its potentialities should be one of the teacher's tasks, as this knowledge will facilitate his/her work with the students. Due to this importance, the work with these materials should also be more present in teacher training courses, so that they are not only used as a source of consultation or activity manual, but as didactic resources that help in the mediation of content with students.

RESUMO: A abordagem dos procedimentos no ensino de ciências é tão necessária
quanto a tradicional abordagem conceitual. Porém, diferente dos conceitos, os procedimentos precisam ser trabalhados com atividades que possibilitem aos alunos realizar ações diferentes do somente escutar e copiar. Dessa forma, na tentativa de abordar procedimentos relacionados à ciência, neste trabalho é apresentada uma escolhidos $10 \mathrm{LD}$ para esse estudo, nos quais todas as atividades presentes foram mapeadas e classificadas de acordo com os objetivos delas. Após essa fase foi
analisado se as atividades contribuíam para desenvolver os procedimentos propostos por Pozo e Crespo (2009). Os livros analisados apresentaram um significativo e diverso número de atividades, mas priorizam alguns tipos de atividades, como
revisão e memorização, as quais não contemplam todos os procedimentos relacionados às Ciências. Como nenhum tipo de atividade contempla todos os
procedimentos, é importante que o professor utilize os diversos tipos para poder contemplar todos os procedimentos propostos. Conhecer o LD e suas potencialidades deve ser uma das tarefas do professor, pois esse conhecimento irá
facilitar seu trabalho com os estudantes. Devido a essa importância, o trabalho com esses materiais deveria estar mais presente também nos cursos de formação de
professores, para que esses não fossem usados apenas como uma fonte de consulta ou manual de atividades, mas como recursos didáticos que auxiliam na mediação dos conteúdos com os alunos. 
conhecimentos considerados chave, mas também compreender como eles são construídos, avaliados e comunicados para a sociedade.

A preocupação com a inclusão dos conteúdos procedimentais e atitudinais em sala de aula está presente em documentos oficiais no Brasil que orientam o trabalho do professor, como nos Parâmetros Curriculares Nacionais de Ciências (PCN) (BRASIL, 1997), nas Diretrizes Curriculares Nacionais (DCN) (BRASIL, 2013) e na Base Nacional Comum Curricular (BNCC) (BRASIL, 2017). Nos PCN podemos encontrar vários trechos que abordam a importância de trabalharmos com procedimentos e atitudes, como quando trata sobre a organização dos conteúdos: "Os conteúdos são apresentados em quatro eixos temáticos [...], levando-se em conta conceitos, procedimentos e atitudes que compõem o ensino desses temas no ensino fundamental” (BRASIL, 1997, p. 15). Ou quando trata sobre avaliação: "Isso é possível ao solicitar ao estudante ou a grupo de estudantes que interprete uma determinada situação fazendo uso de conceitos, atitudes ou procedimentos que estão sendo trabalhados." (BRASIL, 1997, p. 31). Ou ainda ao tratar sobre os critérios de seleção dos conteúdos: "Os conteúdos devem se constituir em fatos, conceitos, procedimentos, atitudes e valores." (BRASIL, 1997, p. 35).

Nas DCN (BRASIL, 2013) também encontramos menção a esses conteúdos indicando que os alunos devem "dominar procedimentos básicos de investigação e produção de conhecimentos científicos” (p. 181). Na BNCC, assim como nos PCN, a importância de trabalhar procedimentos e atitudes é abordada em alguns trechos do documento, um deles ao tratar dos fundamentos pedagógicos da BNCC:

[...] a noção de competência é utilizada no sentido da mobilização e aplicação dos conhecimentos escolares, entendidos de forma ampla (conceitos, procedimentos, valores e atitudes). Assim, ser competente significa ser capaz de, ao se defrontar com um problema, ativar e utilizar o conhecimento construído. (BRASIL, 2017, p. 16).

A mesma preocupação em inserir os conteúdos procedimentais e atitudinais é encontrada nos documentos que orientam a análise e a escolha dos livros didáticos que vão para as escolas, sendo que podemos encontrar referência a esses conteúdos desde os critérios de análise e exclusão das obras (GUIA DO LIVRO DIDÁTICO, 2013) até em citações nos textos do Guia do Livro Didático que é disponibilizado para os professores para a escolha dos livros nas escolas, como exemplo: 
Entretanto é bom salientar que cabe sobretudo ao professor, valorizar a observação cuidadosa, a experimentação, o registro preciso, a comunicação e os demais procedimentos característicos utilizados na produção científica.” (BRASIL, 2014, p. 7).

Levando em consideração que o livro didático (LD) é um recurso em geral disponível para o professor na escola pública, uma vez que é distribuído através do Programa Nacional do Livro Didático (PNLD) pelo governo federal brasileiro às escolas de educação básica da rede pública. Muitas vezes esse livro chega a determinar a organização do trabalho docente, atuando como um verdadeiro manual para muitos professores (FREITAG; MOTA; COSTA, 1997), é importante que nesse recurso existam possibilidades e sugestões de trabalho com os diferentes tipos de conteúdos.

No entanto, apesar de o LD estar presente na escola, muitas vezes este não se encontra na sala de aula. Alguns autores, tais como Megid Neto e Fracalanza (2006), Rosa e Mohr (2016) e Pedreira (2016) afirmam que os professores vêm utilizando os livros didáticos quando vão realizar o planejamento das suas aulas, utilizando-o muitas vezes como fonte para atualização dos conteúdos da sua área de atuação. Esses resultados apontam para uma subutilização do livro em sala de aula, mesmo sendo esse um material que contém no manual do professor orientações para uso durante as aulas, além de apresentar atividades que envolvem conteúdos de diferentes naturezas. O LD pode favorecer a aproximação adequada entre professor e aluno em relação ao objeto do conhecimento, cabendo ao professor o papel de mediador que poderá, dependendo da situação, levar à aprendizagem e ao desenvolvimento dos seus alunos. É a partir dos conhecimentos que os alunos têm do mundo em que vivem que eles poderão construir os conhecimentos apresentados no LD e na escola. O professor pode apresentar ao seu aluno, a depender de sua realidade, diferentes saberes que, muitas vezes, se encontram contemplados nos LD selecionados pelos próprios professores, mas que necessitam de um direcionamento, de uma mediação. Dessa forma, é importante que o professor consiga não só perceber essa abordagem de conteúdos diferenciados presentes nos livros didáticos, mas também utiliza-los durante a orientação da sua prática.

Especificamente tratando sobre os conteúdos procedimentais ou somente procedimentos, iremos encontrá-los nos livros didáticos, nas atividades que são propostas para o aluno. Nesse sentido vale destacar que entendemos como atividade, sendo toda "aquela que demande do aluno algum tipo de ação física ou mental cuja finalidade seja promover a 
Ensino, Saúde e Ambiente - V13 (2), pp. 112-132, AGO. 2020

aprendizagem” (GARCIA, 1997, p. 35). Nos livros são encontradas inúmeras atividades, que vão desde exercícios de fixação a projetos extraclasse, sendo assim, questionamentos como o quanto essas atividades possibilitam que os professores trabalhem os procedimentos relacionados aos conteúdos de ciências, ou se algum procedimento está sendo privilegiado em detrimento a outros, são válidos para entender o quanto os livros didáticos podem ajudar o professor a atender as demandas de aprendizagens dos alunos.

Na tentativa de verificar a contribuição que os livros didáticos podem dar ao professor para abordar procedimentos relacionados à ciência, neste trabalho é apresentada uma análise das atividades propostas em livros didáticos atuais de Biologia e de Ciências.

\section{FUNDAMENTAÇÃO TEÓRICA}

Quando falamos sobre conteúdos procedimentais, ou somente procedimentos, em Ciências rapidamente podemos lembrar de procedimentos de laboratórios ou de pesquisas científicas, como: misturar, pesar, medir, testar, dentre outros. Esses procedimentos são comuns ao fazer Ciências dos profissionais da área e que podem ser importantes também para se aprender sobre Ciências (MILLAR et al., 1994; HOWE, et al., 2000). No entanto, ensinar e aprender Ciências não se devem limitar somente a refazer os passos de cientistas (GILPÉREZ,1996), pois os procedimentos para desenvolver a ciência podem ser diferentes dos procedimentos para aprender a ciência (POZO et al.,1995).

Os procedimentos para ensinar e aprender em Ciências vão além do saber sobre determinado assunto, estão relacionados ao saber fazer, mas não uma simples aplicação de uma técnica e sim a uma ação reflexiva, uma tomada de decisão para solucionar um objetivo específico (PRO BUENO, 1995; POZO et al., 1995; COLL e VALLS, 2000).

Existem algumas sugestões para a classificação desses procedimentos (MILLAR et al., 1994; PRO BUENO, 1998; ORÓ, 1999; COLL e VALLS, 2000; POZO e CRESPO, 2009), mas independente dessa classificação, todos os autores concordam que a atitude do professor é fundamental nesse processo, pois é ele que irá criar as condições para o aprendizado de determinado procedimento. Para esse estudo utilizaremos a classificação sugerida por Pozo e Crespo (2009), por ser uma classificação que contempla procedimentos que não são exclusivos das ciências e que podem contribuir para o aprendizado de outros conteúdos.

Para Pozo e Crespo (2009) os conteúdos procedimentais não são declarativos, não são fáceis de ser verbalizados e talvez por isso sejam difíceis de ser avaliados. Dificilmente os 
alunos aprenderão procedimentos numa aula expositiva, eles precisam realizar atividades, planejadas e intencionais, para aprendê-los (CLEMENT e TERRAZZAN, 2011). Pro Bueno (1998) indica que o professor deve levar em consideração três fatores aos ensinar procedimentos: em que consiste o procedimento, qual o seu contexto e quais os pré-requisitos para aprende-lo. Percebe-se que para atender a esses fatores é necessária uma preparação do professor para compreender o procedimento em si, inseri-lo em um contexto que tenha algum significado para o aluno e o conhecimento do que seu aluno precisaria saber anteriormente para aprender aquele procedimento.

Pozo e Crespo (2009) propõem organizar os procedimentos em cinco categorias de acordo com sua funcionalidade: aquisição de informação, interpretação de informação, análise da informação e realização de inferências, compreensão e organização conceitual da informação e comunicação da informação. Dentro de cada um desses procedimentos gerais outros procedimentos são necessários para seu desenvolvimento, por exemplo para o aluno adquirir novas informações é necessário que ele observe ou busque e selecione novas fontes de informação.

Apesar do reconhecimento da importância de incluir os procedimentos ao se ensinar Ciências (PRO BUENO, 1995; McCORMICK, 1997; BRASIL, 1998; MARTÍNEZLOUSADA; GARCÍA-BARROS, 2003; POZO e CRESPO, 2009; FERREIRA et al., 2010; LÓPEZ-VALENTÍN e GUERRA-RAMOS, 2013; LONGHINI e GOMIDE, 2015; PASTORIO et al.; 2017) a abordagem destes ainda é muito limitada em sala de aula o que reflete numa também limitada publicação de relatos de experiência ou pesquisas sobre o assunto. Xavier et al. (2017) realizaram um levantamento bibliográfico de 1998 (ano de publicação dos PCN) até 2015 e só encontraram cinco trabalhos publicados no Brasil entre artigos, dissertações, teses e outros materiais que tratassem do assunto.

Oró (1999) afirma que é compreensível a atitude dos professores ao privilegiar os aspectos conceituais no seu planejamento, pois quando se aborda conceitos é mais fácil contemplar todas as temáticas do currículo. Porém, para o autor, para se aprender Ciências são necessários o contato e o estabelecimento de relações com os objetos da ciência e isso só é possível através de atividades que envolvam procedimentos.

Se as atividades são a melhor forma de trabalhar com os procedimentos, estas deveriam estar previstas no planejamento do professor. No entanto, atualmente ainda encontramos uma baixa diversificação de modalidades didáticas sendo as aulas exclusivamente expositivas ainda muito frequentes em nossas salas de aula (SANTANA et al., 2016). 
Uma fonte importante de apoio para o planejamento de atividades em sala de aula são os livros didáticos (GOLDBACH et al., 2009; SANTOS et al., 2015), os quais são fontes não só de conhecimento científico como de propostas didáticas (LÓPEZ-VALENTÍN e GUERRA-RAMOS, 2013). Dessa forma, avaliar se as atividades que estão presentes nos livros didáticos podem contribuir para o professor abordar procedimentos é uma forma de entender se este recurso tão presente e entregue gratuitamente para todas as escolas públicas brasileiras pode ajudar os professores a planejar o trabalho com procedimentos em sala de aula.

\section{PERCURSO METODOLÓGICO}

Este trabalho é resultado das atividades desenvolvidas ao longo de uma disciplina do Programa de Pós-Graduação Profissional em Ensino de Ciências da Universidade de Brasília no $1^{\circ}$ semestre de 2017, ministrada por dois dos autores desse trabalho. Participaram dessa disciplina dez alunos, todos professores da educação básica sendo cinco formados em Biologia e cinco em Ciências Naturais.

Cada estudante escolheu um LD para trabalhar ao longo da disciplina, sendo que o critério para escolha deste foi um LD que estava sendo por ele utilizado em sala de aula com seus alunos. No total foram escolhidos sete livros de ensino fundamental e três de ensino médio (Tabela 1). Para esse estudo não será feita uma análise separada para livros de ensino fundamental ou médio, pois o objetivo não foi avaliar os conteúdos conceituais, mas sim os procedimentos, os quais são comuns as Ciências como um todo (Pozo e Crespo, 2009).

Tabela 1 - Livros escolhidos para análise na disciplina pelos alunos com o código de referência para cada livro $(\mathrm{EM}=$ Ensino Médio).

\begin{tabular}{llc}
\hline \multicolumn{1}{c}{ Livro } & \multicolumn{1}{c}{ Autor } & $\begin{array}{c}\text { Código de } \\
\text { Referência }\end{array}$ \\
\hline $\begin{array}{ll}\text { Biologia em contexto - Volume 1 } \\
(\mathrm{EM})\end{array}$ & $\begin{array}{l}\text { José Mariano Amabis e Gilberto } \\
\text { Martho }\end{array}$ & A \\
Biologia $360^{\circ}$ - Volume 2 (EM) & José Arnaldo Favaretto & B \\
Biologia - Volume 3 (EM) & Vivian L. Mendonça & C \\
Ciências Naturais: aprendendo com & Eduardo C. Canto & D
\end{tabular}


o cotidiano $\left(5^{\circ}\right.$ ano $)$

$\begin{array}{llr}\begin{array}{ll}\text { Novo Girassol }- \text { Saberes e Fazeres } \\ \text { do Campo }\left(5^{\circ} \text { ano }\right)\end{array} & \begin{array}{l}\text { Demétrio Gowdak e Eduardo } \\ \text { Martins }\end{array} & \text { F } \\ \text { Companhia das ciências }\left(6^{\circ} \text { ano }\right) & \text { José Manuel et al. } & \text { G } \\ \text { Ciências, nosso corpo }\left(8^{\circ} \text { ano }\right) & \text { Fernando Gerwandsznader } & \text { H } \\ \text { Projeto Araribá }- \text { Ciências }\left(8^{\circ} \text { ano }\right) & \text { Maria Rosa Carnevalle } & \mathrm{I} \\ \text { Projeto Araribá }- \text { Ciências }\left(9^{\circ} \text { ano }\right) & \text { Maria Rosa Carnevalle } & \mathrm{J} \\ \begin{array}{l}\text { Ciências Novo Pensar }- \text { Química e } \\ \text { Física }\left(9^{\circ} \text { ano }\right)\end{array} & \begin{array}{l}\text { Demétrio Gowdak e Eduardo } \\ \text { Martins }\end{array} & \end{array}$

Fonte: autores

Após da escolha do livro foi realizada uma leitura preliminar, pelos estudantes, para a localização e identificação das atividades nele presentes. A partir dessa primeira leitura e das discussões em sala de aula dos referenciais de Goldbach et al (2009), Pozo e Crespo (2009), López-Valentin e Guerra-Ramos (2013) e Santos et al (2015), foram construídas categorias e critérios para classificação dessas atividades. No total foram criadas seis categorias principais, sendo que duas categorias (Revisão e Experimentação) foram subdivididas uma vez que abrigam atividades diferentes, mas que ainda assim se encaixam em uma mesma categoria maior (Quadro 1).

Quadro 1 - Categorias criadas para análise das atividades presentes nos LD

1. Diagnóstico: atividades que exploram o conhecimento prévio do estudante.

\begin{tabular}{|c|c|c|}
\hline \multirow{4}{*}{$\begin{array}{l}\text { 2. Revisão: atividades em que é } \\
\text { necessário "voltar" a conteúdos já } \\
\text { abordados no livro. }\end{array}$} & 2.1. & Memorização e fixação \\
\hline & 2.2 . & Problematização \\
\hline & 2.3 . & $\begin{array}{l}\text { Análise (de texto ou } \\
\text { ns) }\end{array}$ \\
\hline & 2.4 . & $\begin{array}{l}\text { Integração } \\
\text { xtualização) }\end{array}$ \\
\hline \multicolumn{3}{|c|}{ 3. Pesquisa: busca de informações em fontes externas ao livro didático. } \\
\hline \multicolumn{3}{|c|}{ 4. Produção: atividade que visa a produção de modelos, textos, cartazes etc. } \\
\hline & 5.1 & Demonstração \\
\hline
\end{tabular}




\begin{tabular}{|c|c|}
\hline 5. Experimentação & $\begin{array}{l}\text { verificação: } \text { a } \text { atividade } \\
\text { experimental é realizada a fim de } \\
\text { demonstrar um } \\
\text { esperado. }\end{array}$ \\
\hline & $\begin{array}{l}\text { 5.2. Investigativa: a atividade } \\
\text { experimental é realizada a fim de } \\
\text { explorar uma determinada } \\
\text { questão. }\end{array}$ \\
\hline
\end{tabular}

Fonte: autores

Com base nas categorias apresentadas no Quadro 1 foi realizada uma nova leitura das atividades presentes nos LD para quantificar e exemplificar cada categoria. Os exemplos das categorias de cada livro foram apresentados para a turma para que fosse possível unificar a classificação, caso um exemplo apresentasse divergência quanto à classificação, era realizada uma discussão para alcançar um critério consensual. Após a unificação dos critérios de classificação, foi realizada uma nova leitura das atividades para classificar e quantificar todas as categorias presentes em cada livro.

Posteriormente procurou-se identificar em cada categoria se as atividades estavam contemplando os cinco conteúdos procedimentais (aquisição de informação, interpretação de informação, análise da informação e realização de inferências, compreensão e organização conceitual da informação e comunicação da informação) e suas subdivisões propostas por Pozo e Crespo (2009). O objetivo dessa análise era identificar se a atividade possibilitava que o professor trabalhasse aquele procedimento em sala de aula, não foi realizada uma análise da forma como o procedimento estava sendo contemplado ou da qualidade da mesma.

\section{RESULTADOS}

A partir das categorias construídas e validadas nas discussões de sala de aula, cada aluno apresentou uma tabela com o quantitativo de atividades em cada uma das categorias apresentadas no Quadro 1. A consolidação dos dados obtidos pelos alunos está apresentada na Tabela 2. A quantidade de atividades variou bastante de livro para livro, com livros apresentando mais de 600 atividades e outros menos de 100 (Tabela 2). No caso específico desse livro com menos atividades, vale ressaltar que é um livro para séries iniciais, dividido 
em Matemática e Ciências, porém para este trabalho só foram analisadas as atividades de Ciências e talvez, por esse motivo, ele tenha apresentado um número bem inferior de atividades quando comparado com os demais livros.

Apesar dos livros apresentarem de forma geral, muitas atividades, constatamos que estas estão concentradas em algumas categorias, como por exemplo, nas atividades de Revisão (Tabela 2).

Tabela 2 - Síntese quantitativa das atividades encontradas em cada livro analisado.

\begin{tabular}{|c|c|c|c|c|c|c|c|c|c|c|c|}
\hline \multirow[t]{2}{*}{ Categorias } & & \multicolumn{10}{|c|}{ Livros } \\
\hline & & A & B & $\mathrm{C}$ & $\mathrm{D}$ & $\mathrm{E}$ & $\mathrm{F}$ & $\mathrm{G}$ & $\mathrm{H}$ & $\mathrm{I}$ & $\mathrm{J}$ \\
\hline \multirow[t]{2}{*}{ Diagnóstico } & & 0 & 2 & 0 & 7 & 4 & 25 & 3 & 33 & 36 & 22 \\
\hline & Memorização e fixação & 478 & 166 & 363 & 88 & 27 & 279 & 19 & 209 & 94 & 174 \\
\hline \multirow{3}{*}{ Revisão } & Problematização & 6 & 14 & 6 & 6 & 4 & 60 & 22 & 141 & 120 & 2 \\
\hline & Análise & 46 & 126 & 44 & 135 & 12 & 99 & 24 & 121 & 54 & 59 \\
\hline & Integração & 25 & 22 & 16 & 8 & 4 & 65 & 23 & 13 & 25 & 2 \\
\hline Pesquisa & & 25 & 4 & 38 & 21 & 11 & 11 & 19 & 49 & 22 & 23 \\
\hline Produção & & 42 & 2 & 28 & 44 & 10 & 25 & 11 & 40 & 47 & 7 \\
\hline \multirow{2}{*}{ Experimentação } & Demonstração e verificação & 7 & 6 & 5 & 14 & 4 & 13 & 2 & 0 & 0 & 20 \\
\hline & Investigativa & 2 & 1 & 7 & 2 & 1 & 2 & 6 & 17 & 18 & 13 \\
\hline Comunicação oral & & 6 & 7 & 22 & 12 & 13 & 1 & 7 & 35 & 16 & 9 \\
\hline TOTAL & & 637 & 350 & 529 & 337 & 90 & 580 & 136 & 658 & 432 & 331 \\
\hline
\end{tabular}

Cada categoria será apresentada separadamente a seguir:

\section{- Diagnóstico}

Nessa categoria foram incluídas todas as atividades que trabalhavam de alguma forma o conhecimento prévio dos alunos (Figura 1). Esse tipo de atividade foi pouco frequente nos livros analisados, sendo que em alguns aparecem muito pouco ou são inexistentes, como nos livros A e C (Tabela 2). 
Estas imagens mostram seres vivos bastante diferentes, como a onça-pintada, o jacaré, as plantas e a ameba. A onça-pintada, as plantas e a ameba estão fazendo algo em comum, fundamental para a sobrevivência de todos os seres vivos, porém de diferentes maneiras.

Você sabe dizer o que elas estão fazendo? E você sabe dizer por que fazer isso é fundamental?

Neste capítulo veremos que todos os seres vivos do planeta estão inter-relacionados pela alimentação, em uma grande rede planetária.

Figura 1. Exemplo de atividade Diagnóstico presente no livro F

Fonte: Livro F

\section{- Revisão}

As atividades que solicitavam que os alunos voltassem a conteúdos abordados no livro para desenvolvê-la foram consideradas atividades de revisão, ou seja, era necessário que o aluno revisitasse o que foi trabalhado anteriormente para realizar tal atividade (Figura 2). Essa é a categoria mais presente nos livros analisados concentrando mais da metade das atividades neles propostas (Tabela 2).

Dentre as atividades de revisão, existiu uma preponderância das atividades de Memorização e fixação, sendo aquelas que o aluno apenas transcrevia partes do texto, aplicava fórmulas ou buscava as respostas sem nenhuma reflexão (Figura 2). As atividades de revisão que colocavam situações para o aluno pensar e a partir disso elaborar sua resposta, aqui consideradas atividades de Problematização não foram tão frequentes como as de Memorização e fixação. O mesmo pode ser dito para as atividades de Análise, assim classificadas quando os alunos a partir de uma imagem ou texto tinham que elaborar uma resposta. Ainda na categoria Revisão, algumas atividades foram classificadas como de Integração, sendo elas aquelas que promoviam o diálogo entre os saberes escolares e cotidianos dos alunos, sendo, no entanto, a frequência desse tipo de atividades muito baixa (Tabela 2). 
Ensino, Saúde e Ambiente - V13 (2), pp. 112-132, AGO. 2020

(Fuvest-SP) Além da sustentação do corpo, são funções dos ossos:

a. armazenar cálcio e fósforo; produzir hemácias e leucócitos.

b. armazenar cálcio e fósforo; produzir glicogênio.

c. armazenar glicogênio; produzir hemácias e leucócitos.

d. armazenar vitaminas; produzir hemácias e leucócitos.

e. armazenar vitaminas; produzir proteínas do plasma.

Figura 2. Exemplo de atividades de Revisão - Memorização e fixação presente no livro C

Fonte: Livro C

\section{- Pesquisa}

Nessa categoria estão as atividades que provocavam os alunos a buscarem informações fora do LD, as quais também foram pouco frequentes na maioria dos casos (Tabela 2).

Como exemplo desse tipo de atividade temos:

"No Oriente Médio, há indícios de cultivo de trigo datando de cerca de 9 mil anos. Atualmente, existem variedades de trigo com grãos maiores, resistentes ao frio e a doenças. Escolha uma planta de amplo consumo pelo ser humano, como o trigo e faça uma pesquisa a respeito do processo de domesticação." (Exemplo de atividade de Pesquisa presente no livro $\mathrm{C}$ ).

\section{- Produção}

As atividades que provocavam os alunos a produzirem algum produto, seja ele um texto, um cartaz ou um modelo, foram incluídas nessa categoria. A frequência desse tipo de atividade é muito baixa, chegando quase a ser ausente, como no livro B (Tabela 2).

\section{- Experimentação}

Mesmo sabendo que o conceito de experimentação atualmente é bastante amplo, podendo incluir atividades de natureza diversificada, nesse artigo incluímos nessa categoria, atividades características das Ciências como experimentos, manipulação de materiais, observação de espécimes dentre outros. A fim de facilitar a exposição dos resultados, essa categoria assim como a categoria Revisão, foi dividida em subcategorias por englobar 
atividades diversas, mas de mesma natureza, sendo elas: Demonstração/verificação e Investigativas.

Foram classificadas como atividades de Demonstração/verificação, aquelas feitas pelo professor para os alunos, ou de verificação e comprovação de leis e teorias. Como atividades Investigativas foram classificadas aquelas que apresentavam uma perspectiva de investigação a ser realizada pelo próprio aluno (Figura 3).

Diante dessa classificação também constatamos uma baixa frequência desse tipo de atividade, sendo que as atividades Demonstração/ verificação foram mais frequentes em seis livros (A, B, D, E , F e J) e as atividades Investigativas em quatro deles (C, G, H e I), conforme dados da Tabela 2. A seguir seguem exemplos de atividades da categoria Experimentação e suas respectivas subcategorias.

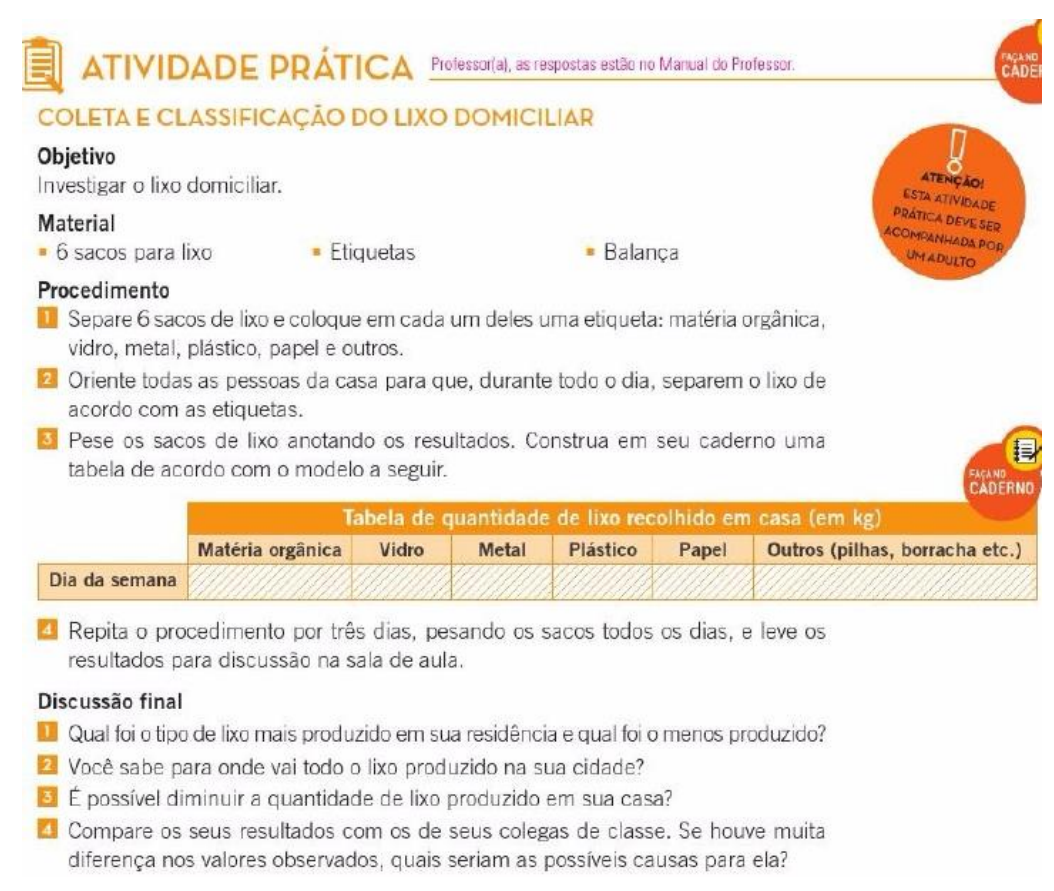

Figura 3 - Exemplo de atividades de Experimentação - Investigação presente no livro F

Fonte: Livro F

\section{- Comunicação}

Nessa categoria foram classificadas as atividades que solicitavam aos alunos que apresentassem seminários, promovessem debates ou júris simulados. Dentre os dez livros analisados esse tipo de atividade foi pouco frequente, sendo maior no livro E $(14,4 \%)$ e menor no livro $\mathrm{F}$ onde esse tipo de atividade foi quase inexistente (Tabela 2). 
Quando analisamos as atividades presentes nos livros na perspectiva proposta por Pozo e Crespo (2009) encontramos um resultado interessante que está representado na Figura 4.

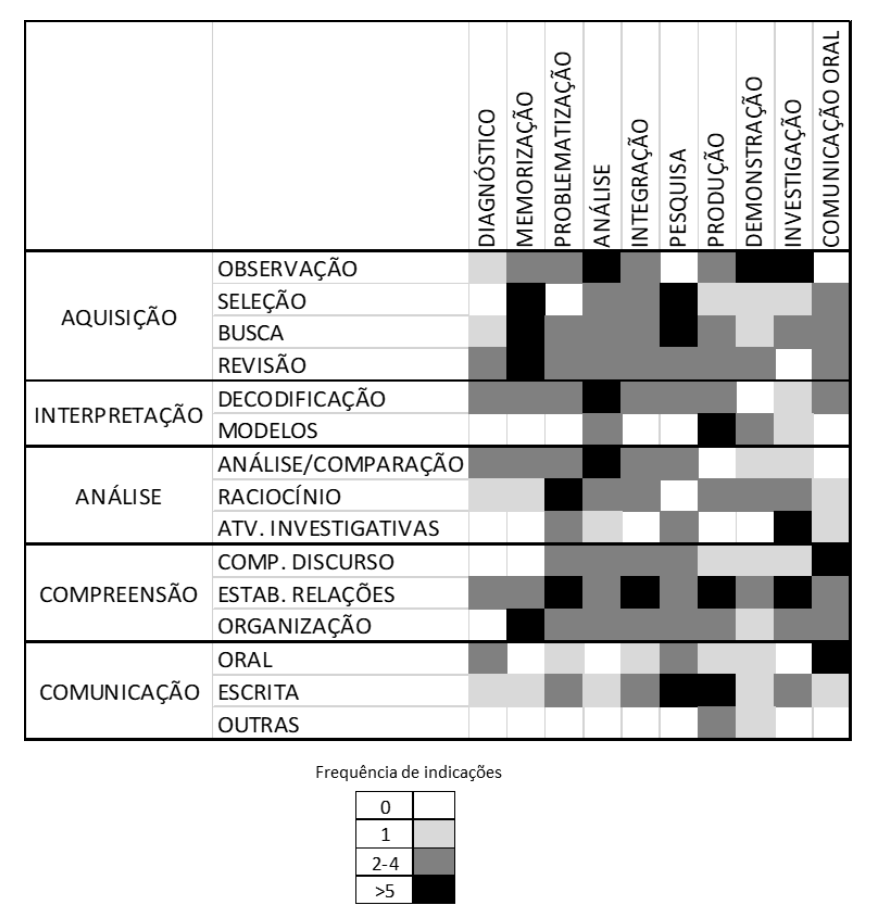

Figura 4 - Relação entre as atividades encontradas nos livros analisados e os procedimentos indicados por Pozo e Crespo (2009).

Fonte: Autores

$\mathrm{Na}$ Figura 4, a tonalidade dos quadrados indica o quanto um determinado tipo de atividade atendeu a um determinado procedimento, dessa forma quando o quadrado está branco significa que aquela atividade não atendeu àquele procedimento e à medida que o quadro vai escurecendo indica que a atividade atendeu mais determinado procedimento. Como podemos observar na Figura 4, as atividades em geral contemplam mais de um procedimento. Apenas três procedimentos são contemplados por todas as atividades: Busca pela informação, Estabelecimento de relações e Comunicação escrita (Figura 4). Outros procedimentos são pouco contemplados nas atividades como a utilização de modelos para explicar situações e a comunicação através de outras formas de expressão.

Outro dado que chama a atenção é que as atividades muito frequentes, como as de memorização, contemplam muito bem alguns procedimentos como aquisição de informação, mas deixam a desejar em outros como comunicação. Já atividades pouco frequentes como experimentação e pesquisa conseguem contemplar muito bem todas as categorias. Dessa 
forma, se o professor priorizar um ou poucos tipos de atividades, ele pode não contemplar todos os procedimentos sugeridos por Pozo e Crespo (2009).

\section{DISCUSSÃO}

A presença do livro didático como recurso de ensino e planejamento do professor é descrito em diversos contextos (GOLDBACH et al., 2009; CLEMENT; TERRAZAN, 2011; LÓPEZ-VALENTÍN e GUERRA-RAMOS, 2013; PEDREIRA, 2016). Alguns autores chegam a afirmar que o LD além de ser uma fonte de conhecimentos e propostas didáticas (LÓPEZ-VALENTÍN e GUERRA-RAMOS, 2013) é utilizado pelos professores como instrumento que organiza, desenvolve ou orienta o conteúdo a ser lecionado e até a sequência didática dada a esse conteúdo (NÚÑEZ, et al. 2003; CARNEIRO, SANTOS e MOL, 2005). Do ponto de vista do ensino de Ciências, com a compreensão de que os procedimentos são tão importantes quanto os conceitos para o aprendizado de ciências, o livro didático deve conter atividades que abordem esses conteúdos.

Apesar do caráter exploratório dos nossos dados, estes indicam que os livros analisados trazem atividades que podem contribuir para o aprendizado de procedimentos. Os livros analisados apresentam um grande quantitativo de atividades com diversos objetivos, fato esse importante para abranger o maior número de procedimentos (LÓPEZ-VALENTÍN e GUERRA-RAMOS, 2013). Para Pozo e Crespo (2009) as ações realizadas em sala de aula limitam-se a explicar (professor), escutar e copiar (alunos). Ao realizar atividades que vão além dessas três ações os professores estão oportunizando aos seus alunos a possibilidade não só de aprender os conteúdos previstos naquela atividade, mas também abrem possibilidades de aprenderem outros conteúdos em outras situações. Como os procedimentos são aprendidos no fazer, cabe ao professor incluir no seu planejamento atividades que coloquem o aluno em situações para executar esses procedimentos.

Os livros analisados apresentam uma diversidade de atividades que pode favorecer o domínio desses procedimentos. Porém, como pode-se constatar, existe uma concentração em atividades de revisão, com poucas atividades de investigação ou pesquisa. Em estudos anteriores encontramos resultados distintos quanto ao quantitativo das atividades em LD. Santos et al. (2017) indicam poucas atividades práticas em livros de Biologia entre 20072012. Já Goldbach et al. (2009), também em livros de Biologia, encontraram uma grande variação nesse quantitativo de 3 a 70, vale ressaltar que ambos trabalhos analisaram somente as atividades práticas, porém o conceito de prática não possibilita a comparação entre eles, 
pois são consideradas como práticas atividades que vão desde experimentos até discussões e debates.

Vale ressaltar que o professor não precisa realizar todas as atividades presentes no livro, mas que tenha um quantitativo suficiente para realizar escolhas dentro de cada realidade.

Ainda sobre os tipos de atividades, verificamos uma baixa ocorrência de atividades que trabalham com o conhecimento prévio dos alunos e um elevado número de atividades de memorização. O levantamento de conhecimentos prévios é uma estratégia importante tanto para o professor, para conhecer sobre seus alunos e planejar suas ações, quanto para o aluno, pois possibilita a mobilização de conhecimentos já adquiridos e possibilita o estabelecimento de novas relações.

Martínez-Losada e García-Barros (2003) e López-Valentín e Guerra-Ramos (2013) também encontraram resultado semelhante ao analisar coleções didáticas mexicanas. A ausência ou restrição de atividades que trabalhem com o conhecimento prévio dos alunos, pode comprometer o trabalho do professor em abordar os demais procedimentos, pois como esse aprendizado é gradual e sequencial, devendo ser planejado intencionalmente, a ausência desse conhecimento por parte do professor pode criar um obstáculo para o seu planejamento (POZO e CRESPO, 2009).

Apesar de todos os procedimentos indicados por Pozo e Crespo (2009) terem sido contemplados, alguns procedimentos foram mais privilegiados que outros. Conforme apresentado, as atividades de memorização foram as mais frequentes, sendo que essas atividades trabalham principalmente alguns procedimentos de aquisição de conhecimento (seleção, busca e revisão). De forma geral essas atividades solicitam que o aluno volte ao texto do capítulo, leia e procure um trecho referente a um determinado assunto e elabore uma resposta, sendo que na maioria das vezes essa resposta nada mais é que uma transcrição do texto selecionado. López-Valentín e Guerra-Ramos (2013) encontraram um resultado diferente, pois além da busca de informações as atividades presentes nos livros mexicanos também priorizavam a aplicação e a comunicação. Apesar disso os autores criticaram as atividades presentes afirmando que os alunos se transformam apenas em buscadores, aplicadores e comunicadores de informação. Martínez-Losada e García-Barros (2003) alertam para o que chamam atividades de baixa exigência, ou seja, atividades que mobilizam poucos conhecimentos (conceituais ou procedimentais). A deficiência em atividades que valorizem os demais procedimentos de interpretação, análise, compreensão e comunicação pode levar a uma limitação no repertório dos alunos em analisar e tomar decisões sobre suas ações diante 
de determinada situação, sendo que para muitos autores essa seria a principal justificativa para se trabalhar os procedimentos (PRO BUENO, 1995; POZO, POSTIGO e CRESPO, 1995; COLL e VALLS, 2000). Clement e Terrazzan (2011) ainda chamam a atenção que em muitas atividades os enunciados em si não se caracterizam como problemas que desafiam os alunos a mobilizarem seus conhecimentos.

\section{CONSIDERAÇÕES FINAIS}

Apesar da necessidade de abordar em sala de aula os conteúdos de forma mais ampla, indo além dos conceitos, ser uma demanda recorrente para os professores, o planejamento e realização disso não é tarefa fácil. A partir de nossa análise, acreditamos que os livros didáticos presentes em nossas escolas podem contribuir com o professor nessa tarefa.

Os livros analisados apresentam um número significativo de atividades, as quais contemplam todos os procedimentos sugeridos por Pozo e Crespo (2009), possibilitando o professor fazer suas escolhas dentro do seu planejamento. Porém, é importante que o professor fique atento para o conjunto das atividades presentes no $\mathrm{LD}$, pois como as atividades de revisão e memorização são as mais comuns, estas não contemplam sozinhas todos os procedimentos necessários para a aprendizagem em Ciências, utilizando uma maior diversidade de tipos de atividades para alcançar mais procedimentos. Atividades como as de problematização, análise, investigação e pesquisa devem ser valorizadas, pois apesar da sua baixa frequência nos livros, contemplam um maior número de procedimentos relacionados às Ciências.

Conhecer o LD e suas potencialidades deve ser uma das tarefas do professor, pois esse conhecimento irá facilitar seu trabalho com os estudantes. Devido a essa importância, o trabalho com esses materiais deveria estar mais presente também nos cursos de formação de professores, para que esses não fossem usados apenas como uma fonte de consulta ou manual de atividades, mas como recursos didáticos que auxiliam na mediação dos conteúdos com os alunos.

\section{REFERÊNCIAS BIBLIOGRÁFICAS}

ANSÓN, J. A.; TORIJA, B. B. Resultados e implicaciones de una propuesta para promover el desenrrollo de las destrezas cientificas en un aula de biología de bachillerato. Revista Electrónica de Enseñaza de las Ciencias, v.16, n.1, p. 132-151, 2017. Disponível em: https://zaguan.unizar.es/record/61552 . Acessado em 15 de fevereiro de 2018. 
BRASIL, MINISTÉRIO DA EDUCAÇÃO. Base Nacional Comum Curricular. Brasília: Ministério da Educação, Secretaria de Educação Básica, 2017. Disponível em: http://basenacionalcomum.mec.gov.br/. Acessado em: 12 de fevereiro de 2018.

BRASIL, MINISTÉRIO DA EDUCAÇÃO. Diretrizes Curriculares Nacionais da Educação Básica. Ministério da Educação, Secretaria de Educação Básica, 2013.Disponível em: http://portal.mec.gov.br/docman/julho-2013-pdf/13677-diretrizes-educacao-basica-2013pdf/file . Acessado em: 28 de fevereiro de 2018.

BRASIL, MINISTÉRIO DA EDUCAÇÃO. Guia de livros didáticos - PNLD 2014 CIÊNCIAS - ENSINO FUNDAMENTAL - ANOS FINAIS. Brasília: Ministério da Educação, Secretaria de Educação Básica, 2013. Disponível em: http://www.fnde.gov.br/programas/programas-do-livro/livro-didatico/guia-do-livrodidatico/item/4661-guia-pnld-2014. Acessado em: 28 de fevereiro de 2018.

BRASIL, MINISTÉRIO DA EDUCAÇÃO. Parâmetros Curriculares Nacionais. Ministério da Educação, Secretaria de Educação Fundamental, 1997. Disponível em:

http://portal.mec.gov.br/seb/arquivos/pdf/livro01.pdf. Acessado em: 01 de março de 2018.

CARNEIRO, M. H.S.; SANTOS, W. L. P., MOL, G. S. Livro didático inovador e professores: uma tensão a ser vencida. Ensaio: Pesquisa em Educação em Ciências. v. 7, n. 2, p.101-113, 2005. Disponível em: http://www.scielo.br/scielo.php?pid=S198321172005000200101\&script=sci_abstract\&tlng=pt. Acessado em: 02 de março de 2016.

CLEMENT, L.; TERRAZZAN, E. A. Atividades didáticas de resolução de problemas e o ensino de conteúdos procedimentais. Revista Electrónica de Investigacíon em Educación em Ciencias, v.6, n.1, p. 87-101, 2011. Disponível em: http://ppct.caicyt.gov.ar/index.php/reiec/article/view/7463 . Acessado em: 02 de março de 2018.

FERREIRA, L. H.; HARTWIG, D. R.; OLIVEIRA, R. C. Ensino experimental de química: uma abordagem investigativa contextualizada. Química Nova na Escola, v. 32, n. 2, p.101106, 2010. Disponível em: http://qnesc.sbq.org.br/online/qnesc32_2/08-PE-5207.pdf Acessado em: 25 de fevereiro de 2018.

FREITAG, B.; MOTTA, V. R.; COSTA, W. F. O estado da arte do livro didático no Brasil. Brasília: INEP, 1987.

GARCÍA, I. R. ¿Qué propuestas de actividades hacen los libros de primaria? Alambique, v. 11, p. 35-43, 1997. Disponível em:

https://www.researchgate.net/publication/39151554_Que_propuestas_de_actividades_hacen_1 os_libros_de_primaria . Acessado em: 20 de fevereiro de 2018.

GIL-PÉREZ, D. New trends in science education. International Journal of Science Education, v. 18, n. 8, p. 889-901, 1996. Disponível em: https://www.tandfonline.com/doi/abs/10.1080/0950069960180802 . Acessado em: 21 de fevereiro de 2018.

GOLDBACH, T.; PAPOULA, N. R. P.; SARDINHA, R. C.; DYSARZ, F. P.; CAPILÉ, B. Atividades práticas em livros didáticos atuais de biologia: investigações e reflexões. Revista Perspectivas da Ciência e Tecnologia, v. 1, n. 1, p. 63-74, 2009. Disponível em: http://revistascientificas.ifrj.edu.br:8080/revista/index.php/revistapct/article/view/10 . Acessado em: 22 de fevereiro de 2018.

HOWE, C.; TOLMIE, A.; DUCHAK-TANNER, V.; RATTRAY, C. Hypothesis testing in science: groups consensus and the acquisition of conceptual and procedural knowledge.

Learning and Instruction, v. 10, p. 361-391, 2000. Disponível em: https://www.sciencedirect.com/science/article/pii/S0959475200000049 . Acessado em: 22 de 
fevereiro de 2018.

KELLY, G. J. Inquiry Teaching and Learning: Philosophical Considerations. In: M. R. MATTHEWS. International Handbook of Research in History, Philosophy and Science Teaching. Springer, Australia, 2014.

LONGHINI, M. D.; GOMIDE, H. A. Conhecimentos atitudinais e procedimentais no processo de aprender astronomia a partir de problemas: um trabalho com alunos do $6^{\circ}$ ano do ensino fundamental. Revista de Ensino de Ciências e Matemática, v. 6, n. 3, p. 54-71, 2015. Disponível em: http://revistapos.cruzeirodosul.edu.br/index.php/rencima/article/view/901. Acessado em: 15 de fevereiro de 2018.

LÓPEZ-VALENTÍN, D. M.; GUERRA-RAMOS, M. T. Análisis de las actividades de aprendizaje incluídas em libros de texto de ciencias naturales para educacíon primaria utilizados em México. Enseñanza de las Ciencias, v. 31, n. 2, p. 173-191, 2013. Disponível $\mathrm{em}$ : https://dialnet.unirioja.es/servlet/articulo?codigo=4317156 . Acessado em: $25 \mathrm{de}$ fevereiro de 2018.

MARTÍNEZ-LOUSADA, C.; GARCÍA-BARROS, S. Las actividades de primaria y eso incluídas em libros escolares: Qué objetivo persiguen? Qué procedimentos enseñan?

Enseñanza de las Ciencias, v. 21, n. 2, p. 243-264, 2003. Disponível em: https://core.ac.uk/download/pdf/38990740.pdf . Acessado em: 05 de março de 2018.

McCORMICK, R. Conceptual and procedural knowledge. International Journal of Technology and Design Education, v. 7, p. 141-159, 1997.

MEGID NETO, J.; FRACALANZA, H. O livro didático de Ciências: problemas e soluções. In: FRACALANZA, Hilário; MEGID NETO, Jorge. O Livro Didático de Ciências no Brasil. Campinas: Editora Komedi, 2006. Disponível em: http://www.scielo.br/pdf/ciedu/v9n2/01.pdf . Acessado em: 02 de fevereiro de 2018.

MILLAR, R.; LUBBEN, F.; GOT, R.; DUGGAN, S. Investigating in the school science laboratory: conceptual and procedural knowledge and their influence on performance. Research Papers in Education, 9(2): 207-248.1994.

NÚÑEZ, I. B.; RAMALHO, B. L.; Silva, I. K. P.; CAMPOS, A. P. N. A seleção dos livros didáticos: um saber necessário ao professor: o caso do ensino de ciências. Revista Iberoamericana de Educación. 2003. Disponível em: http://www.rieoei.org/deloslectores/427Beltran.pdf . Acessado em 13 de agosto de 2014.

ORÓ, I. Conhecimento do meio natural. In: A. ZABALA. Os conteúdos procedimentais em sala de aula. $2^{\text {a }}$. ed. Artmed, Porto Alegre. 1999.

PASTORIO, D. P.; ALVES, J.; VIDMAR, M. P.; SAUERWEIN, I. P. S.; SAUERWEIN, R. A.; WAGNER, B. R.; LORETO, D. N.; DECIAN, E.; PEDRO, F.R.; NEVES, P. S.;

SANTOS, W. G.; GUIDOLIN, J. A. Atividades didáticas de física para o desenvolvimento de conteúdos conceituais e procedimentais no ensino médio. Enseñanza de las Ciencias, extra., p. 1331-1336, 2017. Disponível em:

https://www.raco.cat/index.php/Ensenanza/article/view/336902 Acessado em: 10 de março de 2018.

PEDREIRA, A. J. O uso do livro didático por professores e alunos do Ensino Médio: um estudo em escolas da rede pública de Sobradinho, DF. 2016. Tese (Doutorado) -

Universidade de Brasília, Programa de Pós-Graduação em Educação, Brasília, DF, 2016. Disponível em: http://repositorio.unb.br/handle/10482/22069 . Acessado em: 10 de janeiro de 2017. 
cotidiano ao conhecimento científico. 5. ed. Porto Alegre: Artmed, 2009.

POZO, J. I.; POSTIGO, Y.; CRESPO, M. A. G. Aprendizaje de estrategias para la solución de problemas en ciencias. Alambique, 5(2): 16-26, 1995. Disponível em:

https://repositorio.uam.es/bitstream/handle/10486/662153/aprendizaje_pozo_alambique_1995 .pdf? sequence=3 . Acessado em: 27 de março de 2018.

PRO BUENO, A. Se pueden enseñar contenidos procedimentales en las clases de Ciencias?

Enseñanza de Las Ciencias, v. 1, n. 16, p.21-41, 1998. Disponível em:

https://ddd.uab.cat/pub/edlc/02124521v16n1/02124521v16n1p21.pdf . Acessado em: 26 de março de 2018.

ROSA, M. D.; MOHR, A. Seleção e uso do livro didático: um estudo com professores de Ciências na rede municipal de ensino de Florianópolis. Ensaio - Pesquisa em Educação em Ciências, v. 18, n. 3, p. 97-115, 2016. Disponível em:

http://www.scielo.br/pdf/epec/v18n3/1983-2117-epec-18-03-00097.pdf . Acessado em: 22 de janeiro de 2017.

SANTANA, A. O. R.; CASASCO, E. F. C.; SESSA, P. Modalidades didáticas no ensino de Ciências: o olhar de estudantes da educação básica sobre o processo de aprendizagem.

Revista da SBEnBio, n. 9, 2016. Disponível em:

https://revistas.pucsp.br/index.php/reb/article/viewFile/14979/15125 . Acessado em: 23 de janeiro de 2018.

SANTOS, S. A.; LUCA, A. G.; PIZZATO, M. C.; DEL PINO, J. C. Investigando atividades práticas nos livros didáticos de biologia. Revista Destaques Acadêmicos, v. 7, n. 3, p. 79-95. 2015. Disponível em:

http://www.univates.br/revistas/index.php/destaques/article/viewArticle/481 . Acessado em: 23 de janeiro de 2018.

XAVIER, R. A.; ARRAIS, A. A. M.; GUIMARÃES, E. M.; SILVA, D. M. S.; FALCOMER, V. A. S. Conteúdos procedimentais e atitudinais no ensino de ciências: uma revisão de literatura em publicações brasileiras (1998-2015). Revista de Educação, Ciências e Matemática, v. 7, n. 2, p. 24-34, 2017. Disponível em:

http://publicacoes.unigranrio.edu.br/index.php/recm/article/view/4075/2523 . Acessado em: 15 de dezembro de 2017.

AUTOR 1. DELANO MOODY SIMÕES DA SILVA

AUTOR 2. ANA JÚLIA PEDREIRA

AUTOR 3. LETÍCIA ANJOS

AUTOR 4. LUCAS FREITAS PEREIRA CARNEIRO

AUTOR 5. IAGO OLIVEIRA

AUTOR 6. MARIA EDUARDA PERES DE OLIVEIRA

AUTOR 7. BERNARDO ORICCHIO-RODRIGUES

AUTOR 8. ROSINALDO DOMINGOS DE OLIVEIRA MELO 
AUTOR 9. JOSIANE SIQUEIRA QUINTAS

AUTOR 10. YNGRID RIBEIRO

AUTOR 11. JANYLA MARTINS DE SOUSA

AUTOR 12. FABRICIO FRANÇA LEMOS 